\title{
Caring for young minds in Ireland
}

\author{
Sinéad McGilloway, Michael Donnelly
}

Ir J Psych Med 2000; 17(4): 114-116

"Society...has a choice whether or not to acknowledge the importance of the mental health of its children land young people] and invest in it appropriately or not...if we are to change things, action is needed now".'

Recent years have seen an upsurge of interest among policymakers, researchers and practitioners - throughout the UK and elsewhere - in the growing number of young people aged under 25 who are developing mental health problems. The research evidence ${ }^{2}$ indicates that approximately one in five children and adolescents have mental ill health, a figure all the more disturbing in view of further evidence suggesting that the majority rarely reach specialist services.

Recently, the Mental Health Foundation' reported that approximately two million young people under 20 in the UK have a mental health problem, the range and severity of which tends to increase dramatically with age. The kinds of problems typically reported include emotional and conduct disorders, substance abuse, self harm, eating disorders and psychotic illnesses. For example, anxiety and disruptive disorders account for approximately $12 \%$ and $10 \%$ respectively of all those aged four to 20 years. ${ }^{2}$ While some of these problems are likely to be relatively mild and self-limiting, others such as the psychotic and pervasive developmental disorders will, if left untreated, pose continuing and potentially more serious problems into adulthood.

Furthermore, one in 100 teenagers in the UK attempt suicide and it is now the most common reason for admission to hospital in this age group. Previous research has shown a correlation between attempted suicide and adulttype depressive illness in young people." More recent research in Norway has also shown the suicide risk among male adolescent psychiatric inpatients to be almost seven times higher than in the general population. ${ }^{4}$

In addition, an increased risk of premature death among the entire adolescent psychiatric inpatient population studied $(\mathrm{n}=1,095)$ was reported, particularly in the 25-34 year-old age group. This concurs with recent research conducted in Ireland in which the standardised mortality ratio for psychiatric inpatients aged 15-35 was almost 100 times greater than that reported for the general population.

\footnotetext{
*Sinéad McGilloway, Lecturer in Psychology, Department of Psychology, National University of Ireland at Maynooth, Maynooth, Co Kildare, Ireland.

Michael Donnelly, Reader in Health Services Research, Faculty of Medicine and Health Sciences, Queen's University Belfast, Institute of Clinical Science, Grosvenor Road, Belfast BT12 6BJ, Northern Ireland.

"Correspondence

SUB.MITTED: JULY 11, 2000. ACCEPTED: SEPTEMBER 15, 2000.
}

Even more worrying, therefore, in the context of these findings, is the potentially significant contribution of mental ill health and possible subsequent hospitalisation to the increase in suicidal behaviour and growing suicide rate particularly (but not exclusively) among young men, about which there has been considerable and growing concern in recent years. ${ }^{n-8}$

According to local practitioners in Northern Ireland, mental health services are under-resourced when compared to the rest of the UK and youth mental health services, in particular, are in urgent need of funding and/or re-organisation. This is perhaps most apparent in the acute shortage of specialist provision for vulnerable young people over 14 which, at present, comprises a single, regional, six-bed inpatient and outpatient unit located in Belfast (the Young People's Centre (YPC)). Reports from local practitioners indicate an over-subscription of places to the YPC and a waiting list for admission. Last year, the Department of Health in London allocated $£ 20$ million to improve services for young people, a sizeable chunk of which is likely to be secured for mental health service provision, particularly following recent reports by prestigious bodies such as the Health Advisory Service (HAS)" and the Mental Health Foundation.

Unfortunately, the kind of ring-fenced funding which may be required to meet the mental health needs of young people in Ireland is less forthcoming despite a rapidly developing policy agenda. Each of the four Health and Social Services Boards in Northern Ireland has undertaken a review of, or is in the process of reviewing, youth mental health services.

Completed reviews acknowledge the need for rapid change in service organisation and delivery particularly for those young people moving into their teens. The reports highlight, above all, the importance of adopting the fourtier model of care advocated by the Health Advisory Service and, in turn, by other key bodies and committees including the Mental Health Foundation' and the Audit Commission. ${ }^{10}$

Briefly, this 'template' of mental health service provision for young people describes a strategic approach to commissioning and delivering a comprehensive and fully integrated child and adolescent mental health service which straddles four pivotal levels or 'Tiers' of provision. Tier one services comprise, in large part, primary care professionals, amongst whom the GP is probably best placed to recognise the early symptoms of mental illness. Tier two services refer to direct mental health interventions by individual professionals. Services at Tier three, on the other hand, are more specialised and provided by multidisciplinary teams to assess and treat at-risk groups such as those with eating and developmental disorders. These teams, in turn, act as gatekeepers to Tier four services which include specialist inpatient and secure provision for 
young people with highly specific and complex needs. Tier four professionals are tasked with providing advice and support to professionals in the other three tiers of provision while links between and within Tiers one and two may be developed and strengthened by the work of designated primary mental health workers. According to the HAS, the implementation of the model should be guided by the values and principles (eg. comprehensiveness, integration and development/change) which underpin any high quality service development."

This model, or parts thereof, have been implemented in Great Britain through, for example, the appointment of primary mental health workers. Following its policy statement on the way forward for child and adolescent mental health services in Northern Ireland, " the Department of Health and Social Services has recently indicated that it is planning to undertake a review of psychiatric hospital provision for adolescents (personal communication). The Irish government has gone further by stating its intention to provide 'approved centres' for the care and treatment of children with mental disorders. ${ }^{12}$

The most recent figures show that 130 children and young people aged under 16 (ie. $0.5 \%$ of all admissions) were admitted to psychiatric inpatient care in Ireland during 1998, although this represents a substantial reduction from the 203 admissions during the previous year. ${ }^{13}$ It is notable that under the Mental Health Act (1995) in the south of Ireland (unlike Northern Ireland), anyone under the age of 16 should not be 'detained' in adult psychiatric inpatient units.

There is a strong focus on Tier four services in both jurisdictions. Youth mental health care is an area where an all-Ireland or cross-border approach has the potential to generate important lessons for policy and service provision. Our research has shown an increasing trend in admissions of young Northern Irish teenagers (under 18) to adult psychiatric inpatient care between 1989 and $1995 .{ }^{14}$ In addition, we found that almost one in five of under 18 admissions $(86 / 443,19 \%)$ were aged under 16 when first admitted to adult wards during this six-year period. Moreover, recent census-based research undertaken in Northern Ireland has shown an increase of 33\% between the years 1981 and 1991 - in psychiatric bed occupancy among young men aged $15-24$ years."

Importantly, the recent draft policy statement by the DHSS (NI) states, among other things, that "...children and adolescents should not be accommodated together or with adults." Undoubtedly, the full implementation of well-integrated Tier one and Tier two services - with their emphasis on early detection and treatment - would go a long way toward preventing and/or reducing admissions to hospital (particularly an adult psychiatric ward) for young people with more serious mental health needs. Therefore, strategic efforts to improve the highly specialised Tier four services in both the north and south of Ireland ought to be accompanied by simultaneous attempts to address services at the other three levels particularly with respect to early detection and prevention.

Most important of all, perhaps, is the need to develop: successful intra-and inter-agency working between specialist mental health services and primary and community care-based professionals; closer co-operation between adult and youth mental health services; and effective partnerships between individual mental health (and other) professionals and parents/carers and young people. For example, the direct and active collaboration of GPs with local child and adolescent service providers might help to improve the generally low level of detection and recognition of child and adolescent psychiatric disorder in primary care settings. The severity of symptoms in a young teenager may be underestimated and/or less well recognised by healthcare professionals than in adults with mental ill health because "things are not always as they seem". "Thus, distress in a young teenager may present as a normal reaction to exam pressures or may be due to a complex psychosocial and clinical problem. Community mental health teams and, in particular, adult psychiatrists may - as suggested by Fitzgerald, ${ }^{17}$ - play an important preventive role by adopting a more holistic and 'userfriendly' approach encompassing the treatment of both parents and their children.

In addition, those involved in the lives of young people (eg. parents, carers) act as an initial 'filter' to Tier one services and their role, therefore, in recognising early symptoms of mental ill health and possible suicidal behaviour cannot be under-estimated. Consequently, the implementation of parental training and awareness packages through the health or education sector (or both) ought to receive serious consideration.

Arguably, the resource implications of changes in youth mental health service provision may be significant and any potentially innovative service responses might well be stymied by the considerable uncertainty surrounding the extent to which it might be possible to implement the fourtier model within available resources. However, it should be possible to carry forward at least some of the HAS recommendations (eg. those related to information, awareness and training) within existing funds and staffing arrangements.

Recent political cross-border developments provide an important and timely opportunity to explore the possibilities for comparative and collaborative work on youth (and adult) mental health within the two jurisdictions. For example, the establishment of a national forum or several regional fora would, in the first instance, facilitate shared learning between health boards, Trusts and primary care and specialist mental health professionals with respect to the planning, development and delivery of the full range of youth mental health services.

Collaborative research is required to examine the prevalence, nature, detection and treatment of psychiatric disorder in young Irish people. The benefits or otherwise of hospitalisation both in specialised and adult psychiatric settings also merit investigation. More specifically, further audit and research ought to be conducted in order to:

- translate a locally suited version of the the four-tier model taking account of factors such as rurality, available resources and the economic consequences of service configuration

- help identify 'at-risk' populations and gaps in service provision

- elicit the experiences and views of young people with mental ill health and their parents/carers (despite the well known difficulties in recruiting young research participants)

- evaluate and disseminate preventive and other models of good practice in youth mental health.

Local commissioners and service providers ought to be willing to take on board the results emanating from this kind of research. However, "...the root of the difficulty in 

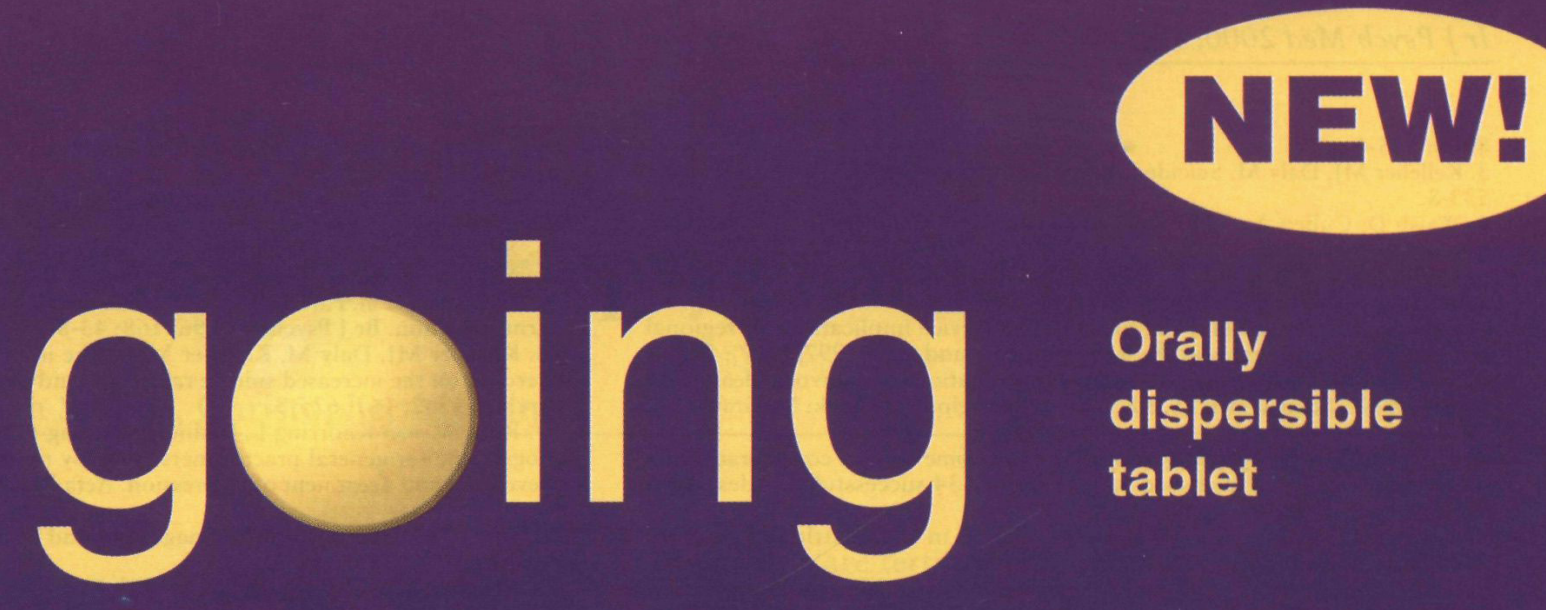

\section{Orally} dispersible tablet
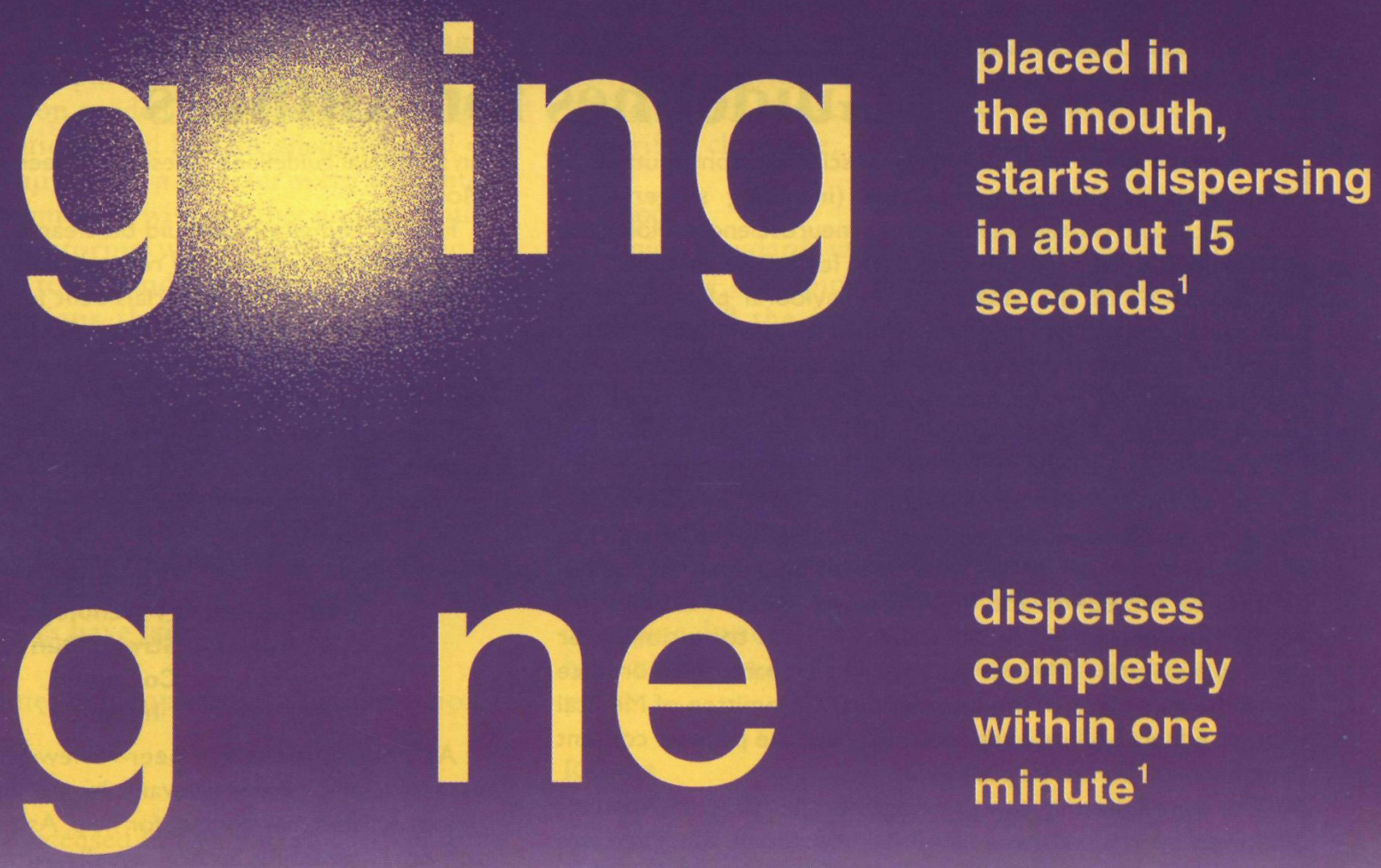

disperses completely within one minute $^{1}$

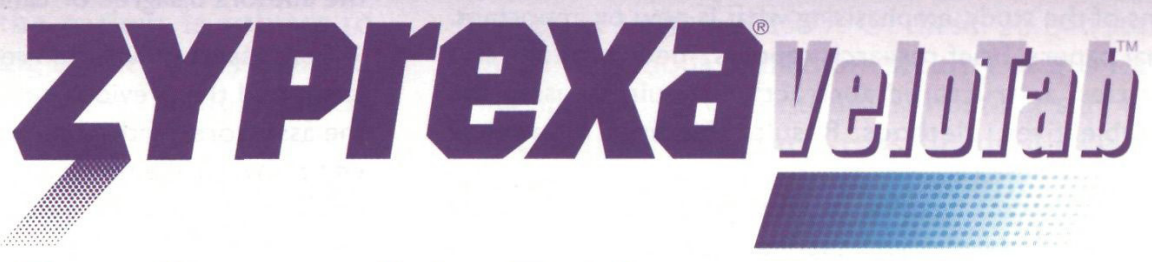

Orodispersible Tablets, Olanzapine

Zyprexa VeloTab is a new oral rapidly dispersing formulation of Zyprexa which offers greater ease of use and aims to enhance compliance.

Zyprexa VeloTab is especially suitable for patients with schizophrenia unable to take oral tablets.

Zyprexa VeloTab is available in $5 \mathrm{mg}$ and $10 \mathrm{mg}$ tablets. 
applying research findings to improve services is that the services are mostly not conceived of as a system of care. Thus, if mental health is the desired outcome, we can only hope to achieve it if services are planned and enabled to work together as a system with this common aim". ${ }^{18}$

\section{References}

1. Mental Health Foundation. Bright futures. Promoting children and young people's mental health. London: Mental Health Foundation, 1999.

2. Target M. Fonaghy P. The psychological treatment of child and adolescent psychintric disorders. In: Roth A, Fonnghy P, (eds). What works for whom: implications and limitations of the research literature. New York: Guilford Press, 1986.

3. Harrington R. Depressive disorder in childhood and adolescence. Chichester: John Wiley, 1993.

4. Kjelsberg E. Adolescent psychiatric inpatients: a high risk group for premature death. Br J Psychiatry 2000; 176: 121-5.

5. Corcoran E, Walsh D. Suicide in psychiatric inpatients in Ireland. Ir J Psych Med 1999; 16:127-31

6. McClure GMC. Suicide in children and adolescents in England and Wales.

Br J Psychiatry 1994: 165: 510-4.
7. Irish Department of Health. National Task Force on Suicide Interim Report. Dublin: Government Publications, 1996.

8. Hawton K, Fagg J, Simkin S, Bale E, Bond A. Trends in deliberate self-harm in Oxford 1985-1995. Br J Psychiatry 1997; 171: 556-60.

9. Health Advisory Service. Together we stand. The commissioning, role and management of child and adolescent mental health services. London: Stationery Office, 1995

10. Audit Commission. Children in mind: child and adolescent mental health services. London: Audit Commission Publications, 1999

11. Health and Social Services Executive. Child and adolescent mental health services: A policy statement (Draft) Beltist: Department of Health and Social Services, 1998.

12. Department of Health. White paper: A new Mental Health Act. Dublin: Stationery Office, 1995

13. Browne C, Daly A, Walsh D. Activiries of Irish Psychiatric Services 1998 Dublin: Health Research Board, 2000.

14. McGilloway S. Donnelly M, Scott, D. Teenagers in adult psychiatric inparient care in Northern Ireland. Ir J Psych Med 2000; 17: 54-8.

15. Prior P. Hayes B. Gender trends in occupancy rates in mental health beds in Northern Ireland. Social Science and Medicine (in press).

16. Steinberg D. Psychiatric problems in adolescence. Primary Care Psychiatry 1996: $2: 79-86$

17. Fitzgerald $M$. The relationship between child, adolescent and adul psychiatry. Ir J Psych Med 1997; 14: 42.

8. Kurtz Z Treating children well London: Mental Health Foundation, 1996.

\section{Guidelines for Authors}

The Journal's aim is to publish original scientific contributions in psychiatry, psychological medicine (including surgery and obstetrics), and related basic sciences (neurosciences, biological, psychological, and social sciences). Its scope includes any subspecialties of the above, eg. behavioural pharmacology, biological psychiatry, child and adolescent psychiatry, mental handicap, forensic psychiatry, psychotherapies, psychiatry of old age, epidemiology, rehabilitation, psychometrics, substance misuse, sexual studies, linguistics, and the history, philosophy and economics of psychiatry.

The Journol will accept original papers, clinical case reports, brief research reports, review articles, perspective articles, historical papers, editorials, practice reviews (medical audits), letters to the editor and book reviews. Review articles are usually invited. Original data papers receive top priority for speedy publication. Manuscripts should be prepared in accordance with the guidelines of the International Committee of Medical Journal Editors.' All case reports must have the patients consent before an article can be published.

The page following the title page should carry an Abstract followed by a list of three to 10 Key Words or short phrases drawn, if possible, from the medical subject headings (MeSH) list of Index Medicus.

The Title, Key Words and Abstract should be chosen to help future literature searchers. The Abstract, up to 150 words for an unstructured or 250 words for the structured abstract, ${ }^{2}$ should state specifically the main purposes, procedures, findings and conclusions of the study, emphasising what is new or important. For original papers, brief research reports, medical audits and review articles, a structured abstract ${ }^{2}$ is required, using the headings Objectives, Methods, Results (Findings for review articles) and Conclusions.

Under the Abstract heading of Method, include wherever applicable the study design, setting, patients/participants (selection criteria, description), interventions, observational and analytical methods and main outcome measures. (For review articles specify the methods of literature search and selection). Under the Abstract heading of Results, give the most important specific data together with their statistical significance.

Timely references should highlight the study's relevance to current research or clinical practice. References to journal articles' ${ }^{3}$ and to books ${ }^{4-6}$ illustrate the 'Vancouver' style,' with journal titles abbreviated as in Index Medicus. The Uniform requirements for manuscripts submitted to biomedical journals' has two paragraphs on statistical guidelines. These have been explained by Bailar and Mosteller.

Figures and graphs should be clear and of good quality, and should be accompanied by relevant data to facilitate redrawing where necessary. All materials sent for publication should be accompanied by a covering letter signed by all the authors, and such material will become the property of the Journal until, and if, publication is refused. Material so referred should not be sent elsewhere for publication. One copy of the manuscript should be retained by the author(s) for reference, and four copies of the manuscript and covering letter, one of these being the original, should be sent to:

\section{The Editor, \\ Irish Journal of Psychological Medicine, 25 Adelaide Street, Dun Laoghaire, Co Dublin, Ireland.}

All contributions are peer-reviewed by three anonymous assessors and, where relevant, by the deputy statistical editor whom authors may contact for help. Assessments will be sent to the corresponding author usually within six weeks. Where revisions are sought prior to publication, authors are advised to return their revision in quadruplicate, incorporating any suggestions which they agree would improve their paper. The covering letter should respond to each comment, numbered, of each assessor, indicating where the revision deals with it, or why the authors disagree or cannot incorporate it.

Each assessor will then receive the authors' revision, covering letter and the previous comments of the other assessors. After the assessors' further comments have been received, the senior editors will make the final decision, including priority and time of publication, and the right to style and if necessary shorten material for publication.

References

1. Internarional Commiree of Medical Jourmal Editors. Uniform requirements for manuscripts subuitred to liomedicil journals. B.MJ 1991: 302: 338-41.

2. Haynes RB, Nulrow CD. Huth EJ. Altman DG, Gardner MJ. More information abstracts revisited. Ann lntern Med 1990; $113: 69.76$.

3. Bailar JC. Mosteller F. Gindelines for statistical reporting in articles for medical journals. Atnl lntern Med 1988 Feb; 108(2): 266-73.

4. Daly LE, Bisurke GJ. McGilvray J. Interpretinion and uses of medical statistics. 4 th ed. Oxford: Blackivell Scientific Publications, 1991: 428-31.

5. Gardner M/, Altman DG, editurs. Statistics with confidence - confidence intervals and statistical guidelines. London: British Medical Jurnal, 1989: 103-5. |Note: British Medical Journal here is the pullisher of a bowk. not the journal B.M.

Americaul Psycliatric Association. Diannustic and statistical manual of mental disurders. Washington DC: American Psychiatric Association, 1987. 